\title{
An Inductive Approach to Calculate the MLE for the Double Exponential Distribution
}

W.J. Hurley

Royal Military College of Canada, hurley-w@rmc.ca

Follow this and additional works at: http://digitalcommons.wayne.edu/jmasm

Part of the Applied Statistics Commons, Social and Behavioral Sciences Commons, and the Statistical Theory Commons

\section{Recommended Citation}

Hurley, W. J. (2009) "An Inductive Approach to Calculate the MLE for the Double Exponential Distribution," Journal of Modern Applied Statistical Methods: Vol. 8 : Iss. 2 , Article 25.

DOI: $10.22237 /$ jmasm/ 1257035040

Available at: http://digitalcommons.wayne.edu/jmasm/vol8/iss2/25

This Brief Report is brought to you for free and open access by the Open Access Journals at DigitalCommons@WayneState. It has been accepted for inclusion in Journal of Modern Applied Statistical Methods by an authorized editor of DigitalCommons@WayneState. 


\title{
An Inductive Approach to Calculate the MLE for the Double Exponential Distribution
}

\author{
W. J. Hurley \\ Royal Military College of Canada
}

Norton (1984) presented a calculation of the MLE for the parameter of the double exponential distribution based on the calculus. An inductive approach is presented here.

Key words: MLE, median, double exponential.

\section{Introduction}

Norton (1984) derived the MLE using a calculus argument. This article shows how to obtain it using a simple induction argument that depends only on knowing the shape of a function of sums of absolute values. Some introductory mathematical statistics textbooks, such as Hogg and Craig (1970) give the answer to be the median - although correct, this does not tell the whole story as Norton points out; this is emphasized here.

\section{Methodology}

It is useful to review the behavior of linear absolute value functions and sums of linear absolute value functions. For example, consider the function

$$
g(x)=|1.8-x|
$$

Its graph is shown in Figure 1. Note that it has a $\mathrm{V}$-shape with a minimum at $x=1.8$. Now consider a sum of two linear absolute value terms:

$$
h(x)=|1.8-x|+|3.2-x| .
$$

W. J. Hurley is a Professor in the Department of Business Administration. Email: hurleyw@rmc.ca.
Plots of this function and its components, $\mid 1.8$ $\mathrm{x} \mid$ and $|3.2-\mathrm{x}|$, are shown in Figure 2. Note that $h(x)$ takes a minimum at all points in the interval $1.8 \leq x \leq 3.2$.

The MLE

The double exponential distribution is given by

$$
f(x)=\frac{1}{2} e^{-|x-\theta|}, \quad-\infty<x<\infty .
$$

For the sample $\left\{x_{1}, x_{2}, \ldots, x_{n}\right\}$, the loglikelihood function is

$$
\ell(\theta)=n \ln (1 / 2)-\sum_{i}\left|x_{i}-\theta\right|
$$

Maximizing this function with respect to $\theta$ is equivalent to minimizing

$$
g_{n}(\theta)=\sum_{i}\left|x_{i}-\theta\right|
$$

To obtain the MLE for general $n$, begin with the case $n=1$ where $g_{1}(\theta)=\left|x_{1}-\theta\right|$. This function has a minimum at $\theta=x_{1}$, hence, for $n$ $=1$, the MLE is

$$
\theta^{M L E}=x_{1}
$$




\section{HURLEY}

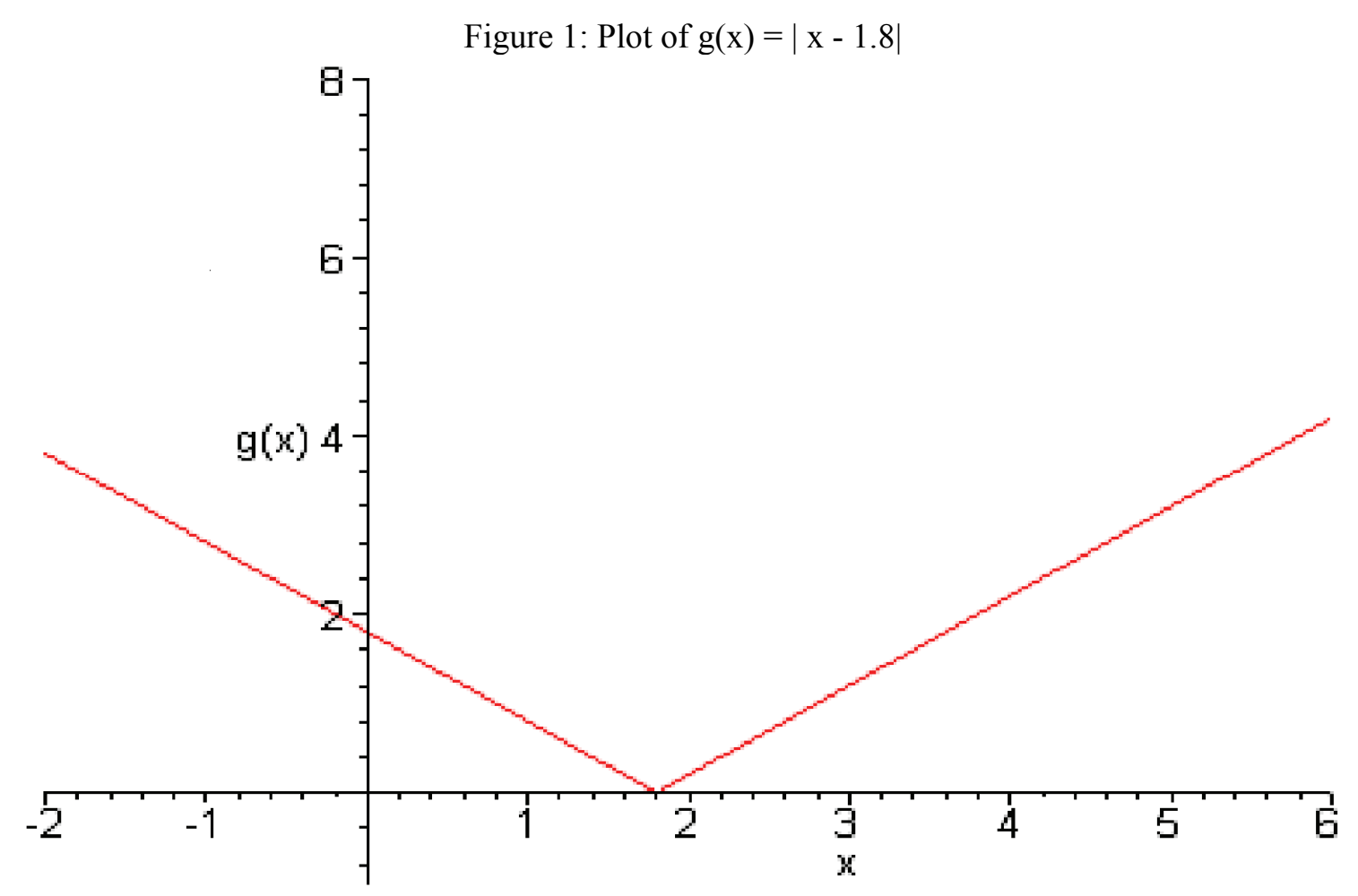

Figure 2: Plot of $h(x)=|1.8-x|+|3.2-x|$

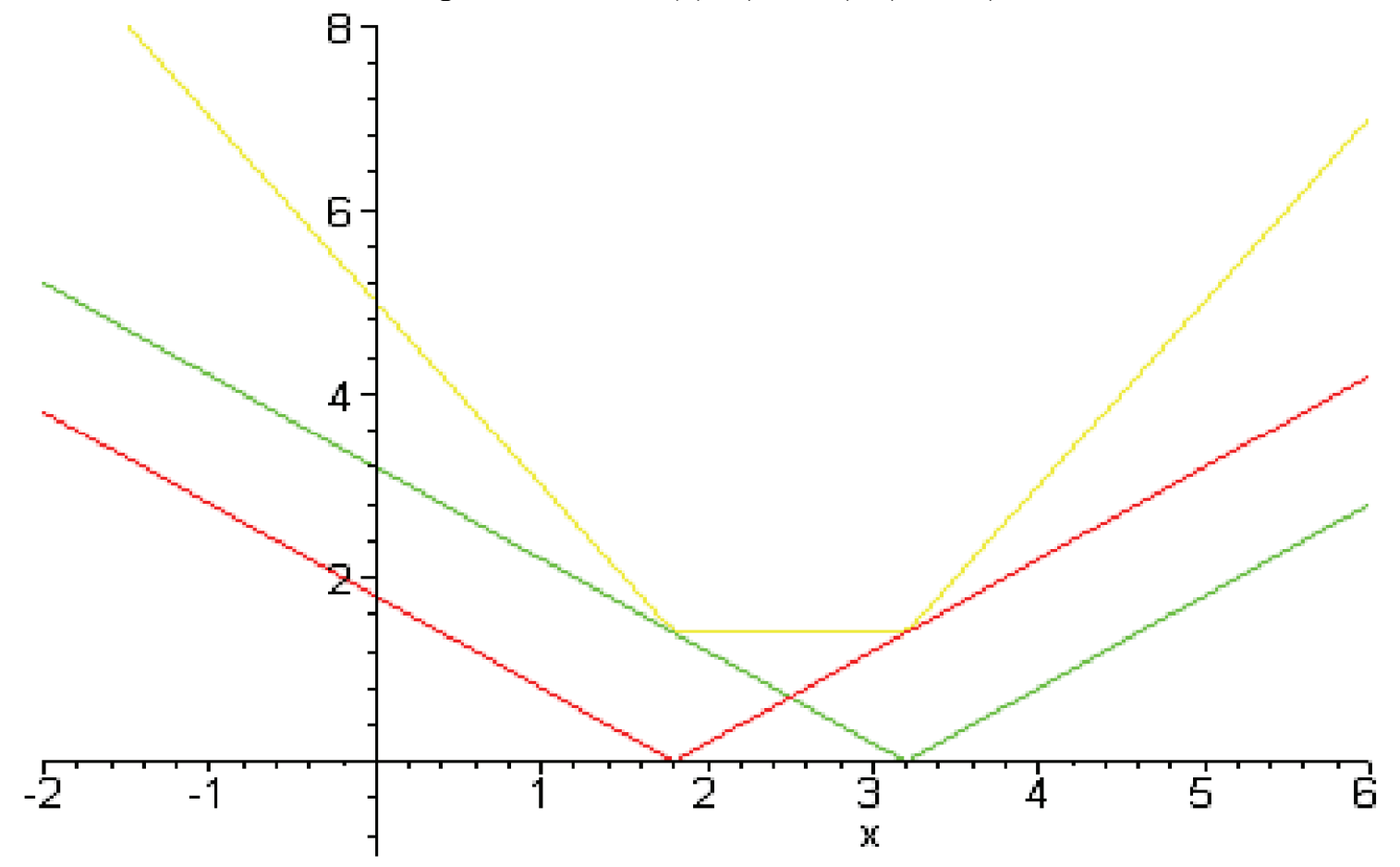


Now, consider the case $n=2$. For the purposes herein it is useful to order the observations, thus, suppose that the sample is $\left\{x_{(1)}, x_{(2)}\right\}$ where $x_{(1)}<x_{(2)}$. The value of $\theta$ which minimizes must now be found using

$$
g_{2}(\theta)=\left|x_{(1)}-\theta\right|+\left|x_{(2)}-\theta\right|
$$

Based on the above, this function takes the form

$$
g_{2}(\theta)=\left\{\begin{array}{cc}
-2 \theta+x_{(1)}+x_{(2)} & \theta \leq x_{(1)} \\
x_{(2)}-x_{(1)} & x_{(1)} \leq \theta \leq x_{(2)} \\
2 \theta-x_{(1)}-x_{(2)} & \theta \geq x_{(2)}
\end{array}\right\}
$$

and has a minimum at any point $\theta$ in the interval $x_{(1)} \leq \theta \leq x_{(2)}$. Hence the MLE for $n=2$ is

$$
\theta^{M L E}=\lambda x_{(1)}+(1-\lambda) x_{(2)}, \quad 0 \leq \lambda \leq 1 .
$$

For this case, the median is defined $\left(x_{(1)}+x_{(2)}\right) / 2$ and is a solution, but it is not the only solution.

Next, consider the case $n=3$ with an ordered sample $x_{(1)} \leq x_{(2)} \leq x_{(3)}$. Using the same graphical analysis, it can be shown that

$$
g_{3}(\theta)=\left|x_{(1)}-\theta\right|+\left|x_{(2)}-\theta\right|+\left|x_{(3)}-\theta\right|
$$

has a unique minimum at $\theta=x_{(2)}$, the median. In the case $n=4$, the solution is

$$
\theta^{M L E}=\lambda x_{(2)}+(1-\lambda) x_{(3)}, \quad 0 \leq \lambda \leq 1 .
$$

Thus, the median is a solution, but not the only solution.

\section{Conclusion}

Extending the argument for general $n$ is straightforward. It is the median, $x_{((x+1) / 2)}$, if $n$ is odd and the generalized median, $\lambda x_{(n / 2)}+(1-\lambda) x_{(n / 2+1)}$, when $n$ is even.

\section{References}

Hogg, R. V., \& Craig, A. T. (1970). Introduction to Mathematical Statistics, $\left(3^{\text {rd }}\right.$ Ed.). New York, NY: MacMillan Publishing Company.

Norton, R. M. (1984). The double exponential distribution: Using calculus to find a maximum likelihood estimator. The American Statistician, 38(2), 135-136. 